\title{
Cymbopogon nardus Mediated Synthesis of Ag Nanoparticles for the Photocatalytic Degradation of 2,4-Dicholorophenoxyacetic Acid
}

\author{
N.S. Kamarudin ${ }^{1}$, R. Jusoh ${ }^{1 *}$, H.D. Setiabudi ${ }^{1}$, N.W.C. Jusoh ${ }^{2}$, N.F. Jaafar ${ }^{3}$, N.F. Sukor ${ }^{1}$ \\ ${ }^{1}$ Faculty of Chemical and Natural Resources Engineering, Universiti Malaysia Pahang, 26300 \\ Gambang Kuantan, Pahang, Malaysia \\ ${ }^{2}$ Department of Chemical Process Engineering, Malaysia-Japan International Institute of Technology \\ (MJIIT), Universiti Teknologi Malaysia, Kuala Lumpur, Jalan Sultan Yahya Petra, 54100 Kuala \\ Lumpur, Malaysia \\ ${ }^{3}$ School of Chemical Sciences, Universiti Sains Malaysia, 11800 USM Penang, Malaysia
}

Received: 1st October 2018; Revised: $12^{\text {nd }}$ November 2018; Accepted: $12^{\text {nd }}$ December 2018; Available online: 25th January 2019; Published regularly: April 2019

\begin{abstract}
Advanced extraction method such as simultaneous ultrasonic-hydrodistillation (UAE-HD) extraction method has been proved to increased extraction yield of plant material yet the application of this method in the preparation of metal nanoparticles has not been studied. In this study, Cymbopogon nardus (C.N) extracted via UAE-HD extraction method was used to synthesis silver (Ag) nanoparticles. XRD and TEM analysis confirms the formation of spherical shape Ag nanoparticles with size ranging between 10-50 $\mathrm{nm}$. FTIR spectra suggest the presence of bioactive compounds in the C.N leaves extract that may responsible to the stabilization and reduction of $\mathrm{Ag}$ ions $\left(\mathrm{Ag}^{+}\right)$to metallic $\mathrm{Ag}$ nanoparticles $\left(\mathrm{Ag}^{0}\right)$. The TPC analysis successfully proved that huge number of phenolic compound greatly involved in the nanoparticles synthesis process. Next, the catalytic activity of the synthesized Ag nanoparticles was tested towards the degradation of 2,4-Dicholorophenoxyacetic acid herbicide with remarkable degradation performance up to $98 \%$. Kinetic study confirms that surface reaction was the controlling step of the catalytic process. Copyright (C) 2019 BCREC Group. All rights reserved
\end{abstract}

Keywords: Silver Nanoparticles; Cymbopogon nardus; Ultrasonic-hydrodistillation; 2,4-D herbicide

How to Cite: Kamarudin, N.S., Jusoh, R., Setiabudi, H.D., Jusoh, N.W.C., Jaafar, N.F., Sukor, N.F. (2019). Cymbopogon nardus Mediated Synthesis of Ag Nanoparticles for the Photocatalytic Degradation of 2,4-Dicholorophenoxyacetic Acid. Bulletin of Chemical Reaction Engineering \& Catalysis, 14 (1): 173-181 (doi:10.9767/bcrec.14.1.3321.173-181)

Permalink/DOI: https://doi.org/10.9767/bcrec.14.1.3321.173-181

\section{Introduction}

The presence of various herbicide and pesticide in wastewater due to industrialization would cause severe environmental and health problems due to the toxicity of these hazardous organic compounds. 2,4-Dichlorophenoxyacetic

\footnotetext{
* Corresponding Author.

E-mail: rohayu@ump.edu.my (R. Jusoh)

Telp: 60-9-5492815
}

acid (2,4-D) is the most widely used herbicides in the agriculture industries [1]. However, due to its high biological and chemical stability, these herbicide was very difficult to decompose and it can causes injury to the heart and central nervous system [2]. Therefore, degradation and conversion of this herbicide into harmless mineral is crucial before it can be discharged to the environment [3]. Photocatalytic degradation has been considered as one of the most efficient and 
economical methods to remove organic chemical in wastewater [4]. This is due to its advantages including low energy consumption and zero generation of secondary pollution [5].

Nowadays, metal nanoparticles especially silver (Ag) nanoparticles have been widely used as photocatalyst for photocatalytic degradation process. Synthesis of Ag nanoparticles using plant extract has received an increasing attention due to the growing need to expand environmentally friendly and green technologies in material synthesis [6]. Plant extract are basically enriched with phenolic compounds such as flavonoids, terpenoids, tannins, and gallic acid that act as a reducing agent as well as capping and stabilizing agent in the synthesis of Ag nanoparticles [7]. Previously, the synthesis of Ag nanoparticless using Murraya koenigi, Piper betle, and Plumbago zeylanica leaves extract had been reported in the literature using classical aqueous extraction method [8]. However, the synthesis of Ag nanoparticles by using plant phenolic compound extracted from simultaneous ultrasonic-hydrodistillation method is still rare since most of the studies only used conventional aqueous extraction to extract plant phenolic compound for the synthesis of nanoparticles [9-11]. The combination of ultrasonic method with hydrodistillation technique was known to greatly enhance the yield of phenolic compound extracted from plant material [12]. These may largely affect the characteristic of the nanoparticless formed as the synthesis route is significantly contributed by the plant extract compound.

Cymbopogon nardus (C.N) is a plant that belongs to the Poaceae (grass) family, which easily grown in Malaysia. It is widely used in the industries of perfumery, foods preservation and aromatherapy. Due to the fact that this plant consists of various phenolic compounds, C.N has become an interesting alternative to be studied as a synthesis media for Ag nanoparticless preparation. Phenolic compounds, such as: flavonoid, terpenoids, tannins, gallic acid and sterols, have been reportedly important for the reduction of $\mathrm{Ag}$ ions to $\mathrm{Ag}$ nanoparticles during synthesis process as well as capping of nanoparticles [13-17]. Therefore, this paper aims to synthesis Ag nanoparticles via electrochemical method using C.N leaves extract as a media in which the C.N leaves was priory extracted by using simultaneous ultrasonichydrodistillation method. The green $\mathrm{Ag}$ nanoparticles was then analyzed by X-ray powder diffraction (XRD), Transmission electron microscopy (TEM) and Fourier transforms infrared spectroscopy (FTIR). Next, the photo- catalytic activity of the synthesized $\mathrm{Ag}$ nanoparticles was studied towards the degradation of 2,4-D.

\section{Materials and Methods}

\subsection{Materials}

The fresh leaves of Cymbopogon Nardus (C.N) were obtained from Jabatan Pertanian Negeri Pahang. The $\mathrm{Ag}$ and $\mathrm{Pt}$ plates of greater than $99 \%$ purity were used as electrodes and were obtained from Nilaco, Japan. 2,4-Dicholorophenoxyacetic acid (2,4-D) was purchased from Merck, Malaysia. All chemicals used in this study were high analytical grade, while all the aqueous solution was prepared using deionized water.

\subsection{Preparation of Cymbopogon nardus Leaves Extract and Silver Nanoparticles}

Cymbopogon nardus (C.N) leaves extract were thoroughly washed using deionized water, dried at $25^{\circ} \mathrm{C}$ for 3 days and grinded until it becomes powder. $10 \mathrm{~g}$ of the powder were immersed in $500 \mathrm{~mL}$ of deionized water. The solution was placed in the ultrasonic bath with the ultrasonic frequency of $9 \mathrm{~Hz}$ for $30 \mathrm{~min}$. Then, the solution was transferred to a roundbottomed flask in order to carry out the hydrodistillation process for 8 hours. The vapourised mixture in the distillation unit is then routed to a process namely condensation whereby the extracted oil solution was collected in a receiving vessel and stored in a sample bottle. The obtained extract solution C.N leaves was used to synthesis Ag nanoparticles via electrochemical method. Electrochemical cell which consists of a two-electrode configuration of Ag plate ( 2 $\mathrm{cm} \times 2 \mathrm{~cm})$ anode and a platinum plate $(2 \mathrm{~cm} \times$ $2 \mathrm{~cm}$ ) cathode was used. Electrolysis was conducted at a constant current of $480 \times 10^{-3} \mathrm{~A}$ and $273 \mathrm{~K}$ under air atmosphere [18]. Then, the solution product mixture was immersed in the water bath at $80^{\circ} \mathrm{C}$ before dry overnight in an oven at $110^{\circ} \mathrm{C}$. The obtained powder was denoted as $\mathrm{Ag}_{\mathrm{CN}}$. The mentioned electrolysis method was also conducted with the absence of plant extract and the sample was denoted as $\mathrm{Ag}_{\mathrm{B}}$.

\subsection{Determination of Total Phenolic Contents}

The amount of total phenolics in C.N leaves extract was determined using Folin-Ciocalteu reagent with gallic acid as a standard. Briefly, $0.5 \mathrm{~mL}$ of extract solution was mixed with $2.5 \mathrm{~mL}$ of Folin-Ciocalteu reagent (10\%). After $5 \mathrm{~min}, 2 \mathrm{~mL}$ of $\mathrm{Na}_{2} \mathrm{CO}_{3}(0.75 \%)$ was added and 
the mixture was reacted for $2 \mathrm{~h}$ at room temperature. The absorbance was measured at $765 \mathrm{~nm}$ using UV-visible spectrophotometer and the total phenolic content was determined per gallic acid equivalent (GAE) mg sample [19].

\subsection{Characterization of Ag Nanoparticles}

UV-Visible spectroscopy measurements of green synthesis $\mathrm{Ag}$ nanoparticles were performed using Perkin Elemer U-1800 UV-vis Spectrophotometer. The crystalline structure of $\mathrm{Ag}$ nanoparticles was investigate using X-ray diffraction (XRD) recorded on a D8 ADVANCE Bruker X-ray diffractometer using $\mathrm{Cu}-\mathrm{K} \alpha$ ra-

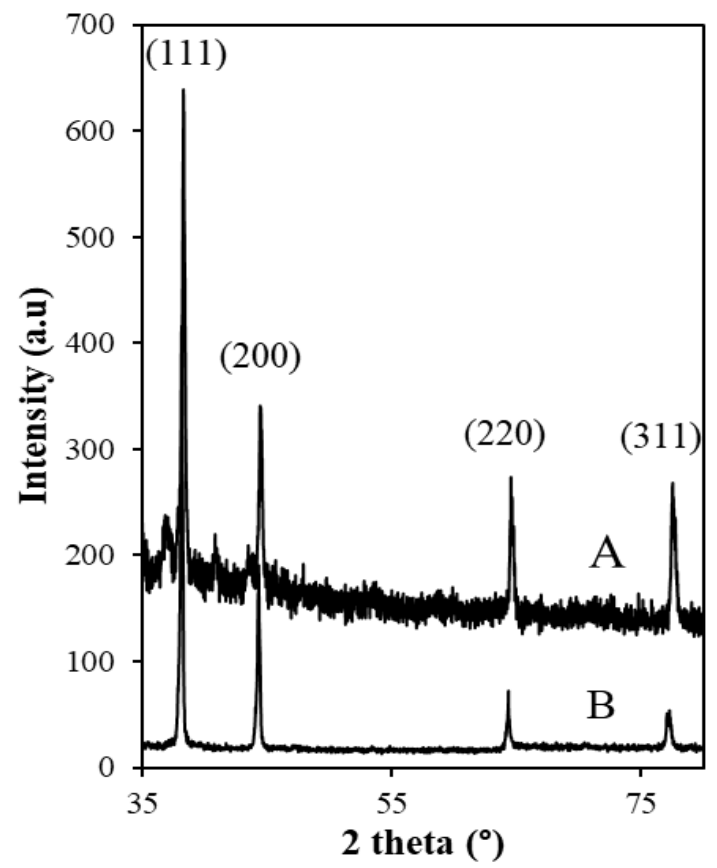

Figure 1. XRD pattern of (A) $A_{C N}$; $(B) A_{B}$ nanoparticles
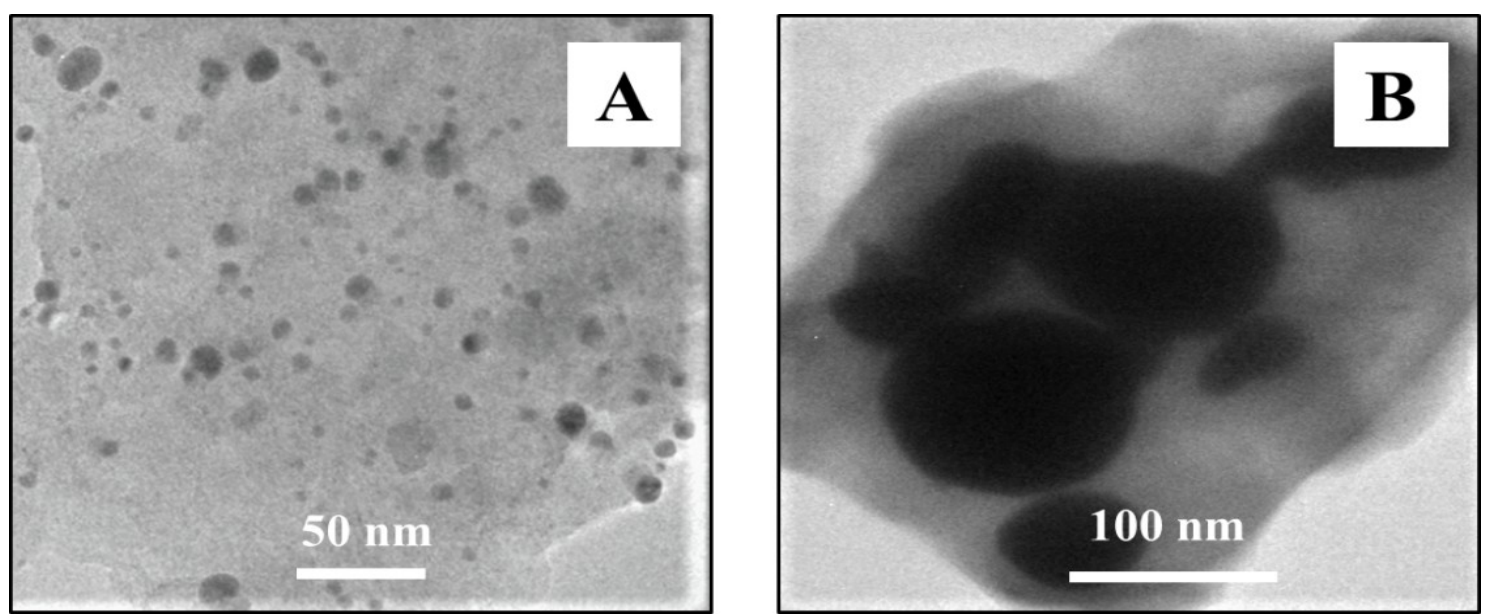

Figure 2. TEM image of (A) $\mathrm{Ag}_{\mathrm{CN}}$ and (B) $\mathrm{Ag}_{\mathrm{B}}$ nanoparticles diation at a $2 \theta$ angle ranging from $2^{\circ}$ to $90^{\circ}$. The presence of functional group in $\mathrm{Ag}$ synthesized using C.N leaves were identified Fourier transforms infrared (FTIR) spectra (Perkin Elmer Spectrum GX FTIR Spectrometer) using $\mathrm{KBr}$ method with a scan range of $500-4000 \mathrm{~cm}^{-}$ 1. The morphology and size of Ag nanoparticles was examined using a Transmission electron microscopy (TEM) (JEOL JEM-2100F).

\subsection{Photocatalytic Degradation of 2,4-D}

The photocatalytic activity of Ag nanoparticles was evaluated on photodegradation of 2,4-D solution under UV light. The experiments were carried out by adding Ag nanoparticles $(0.01 \mathrm{~g} / \mathrm{L})$ into $500 \mathrm{~mL}$ of $2,4-\mathrm{D}$ solution $(10 \mathrm{mg} / \mathrm{L})$ in a batch reactor fixed with $\mathrm{UV}$ lamp $(4 \times 9 \mathrm{~W} ; 254 \mathrm{~nm})$ and cooling system. The suspension was stirred constantly at 700 rpm for $30 \mathrm{~min}$ in dark condition to achieve adsorption-desorption equilibrium and then the reaction irradiated for 3 hours. At a regular interval of time, $4 \mathrm{~mL}$ of the suspension was withdrawn and centrifuged at 13,000 rpm for $10 \mathrm{~min}$. The solution was monitored using UVVIS spectrometer to measure the absorbance at a wavelength $227 \mathrm{~nm}$.

\section{Results and Discussion}

\subsection{X-ray Diffraction (XRD) Analysis}

The XRD pattern of the synthesized Ag nanoparticles is shown in Figure 1. Both $\mathrm{Ag}_{\mathrm{CN}}$ and $\mathrm{Ag}_{\mathrm{B}}$ demonstrated the peak appeared at $38.68^{\circ}, 44.1^{\circ}, 64.11^{\circ}$, and $77.4^{\circ}$ corresponding to $111,200,220$, and 222 plane that could be indexed to the standard phase of metallic silver (JCPDS file no. 893722) [20]. XRD pattern for $\mathrm{Ag}_{\mathrm{CN}}$ exhibits some additional peaks that may attribute to the presence of phenolic com- 
pounds from leaves extract which may be responsible in stabilization of $\mathrm{Ag}$ nanoparticles [21]. Meanwhile, XRD pattern of $\mathrm{Ag}_{B}$ shows the absence of any impurity peak indicating the purity of prepared $\mathrm{Ag}$ [22]. The average sizes of the crystals in each of the samples were determined via Scherrer's formula in Equation (1):

$$
D=\frac{k \lambda}{\beta \cos \theta}
$$

where $D$ stands for the crystallite size of the powder, $k$ is Scherer's constant (0.9), $\lambda$ is $0.1541 \mathrm{~nm}$ which refer to the X-ray wavelength, $\theta$ is the Bragg diffraction angle, $\beta$ is the full width at half maximum (FWHM) intensity in of the (111) plane in radians. FWHM can be determined by taking the highest point of the (111) peak and walk along the slopes on both sides until it trespass half that maximum value. The difference in ordinate (x-axis) of these two points is called FWHM. After that, the difference between these $\mathrm{x}$-axis $(\Delta \mathrm{x})$ was multiplied by $\pi$ (in radian) and divided by 180 $(\beta=(\Delta x \times \pi) / 180)$ [23]. Based on the calculated value, the size of $A_{\mathrm{g}} \mathrm{CN}$ was found to be $8.40 \mathrm{~nm}$, while $\mathrm{Ag}_{\mathrm{B}}$ nanoparticles displays a massive size of nanoparticless $(83.81 \mathrm{~nm})$. This result might be due to the presence of phenolic compounds in C.N leaves extract encapsulated the surface of $\mathrm{Ag}_{\mathrm{CN}}$ catalyst and keeps the $\mathrm{Ag}_{\mathrm{CN}}$ catalyst away from each other to prevent aggregation and subsequently control the growth of particles [13]. However, large size of $\mathrm{Ag}_{\mathrm{B}}$ nanoparti-

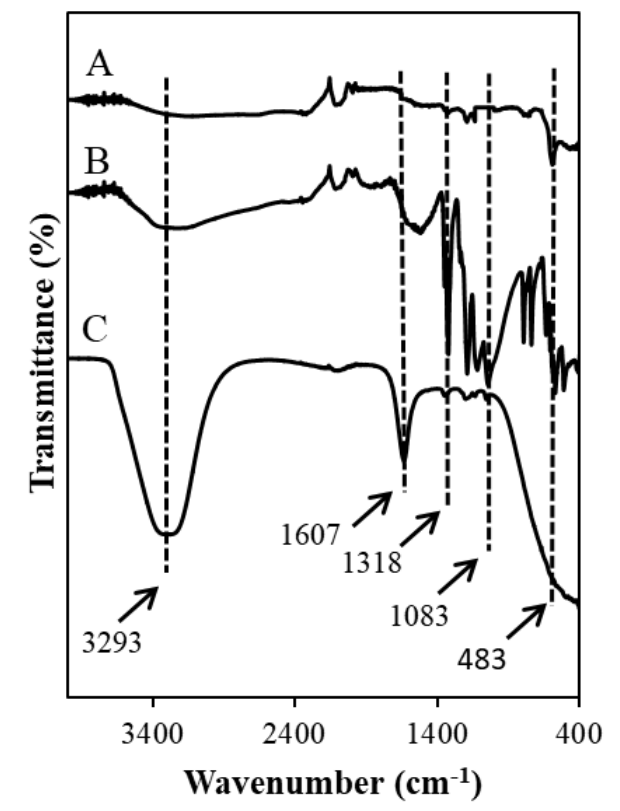

Figure 3. FTIR spectra of (A) $\mathrm{Ag}_{\mathrm{B}}$, (B) $\mathrm{Ag}_{\mathrm{CN}}$ and (C) C.N leave extract cles was obtained due to the absence of phenolic compounds to encapsulate and control the growth of nanoparticles [24].

\subsection{Transmission Electron Microscopy (TEM)}

The size and morphology of Ag nanoparticles was examined using TEM image as shown in Figure 2. From this image, it was confirmed that the Ag nanoparticles were predominantly spherical in shape. Figure 2(A) demonstrates a well-dispersed Ag nanoparticles ranged between 5-20 nm without any aggregation. As compared to the $A g_{\mathrm{CN}}$, the TEM image in Figure 2(B) revealed a much larger nanoparticless of $\mathrm{Ag}_{\mathrm{B}}$ with an average size around 50$100 \mathrm{~nm}$, with particles agglomeration was observed in the morphology image. This may due to the phenolic compounds present in C.N leaves extract that responsible in capping the $\mathrm{Ag}_{\mathrm{CN}}$ nanoparticles, which then restricts the growth of nanoparticless [25]. Previous study also shows that Ag synthesized using Coccinia grandis leaves extract produces small size of particle ranged between 20 to $30 \mathrm{~nm}$ [26]. Remarkably, this result is also in agreement with the XRD analysis in terms of the size determination.



Figure 4. Performance of $\mathrm{Ag}_{\mathrm{CN}}$ and $\mathrm{Ag}_{\mathrm{B}}$ nanoparticles on degradation of 2,4-D (Conc = $10 \mathrm{mg} \mathrm{L}^{-1}, \mathrm{pH}=3$, Light $=$ UV light, $\mathrm{Ag}=0.01$ $\mathrm{g} \mathrm{L}^{-1}$ ) 


\subsection{Fourier Transforms Infrared Spectroscopy (FTIR)}

The FTIR analysis was used to determine the organic compounds present on the nanoparticless and their involvement in the reduction of $\mathrm{Ag}$ ions $\left(\mathrm{Ag}^{+}\right)$to the metallic $\mathrm{Ag}$ nanoparticles $\left(\mathrm{Ag}^{0}\right)$. The FTIR spectra of C.N leave extract, $\mathrm{Ag}_{\mathrm{CN}}$, and $\mathrm{Ag}_{\mathrm{B}}$ was illustrated in Fig. 3. The peak at $3293 \mathrm{~cm}^{-1}$ that corresponded to the phenol $-\mathrm{OH}$ stretching in C.N leaves extract shifted to higher frequency of $3300 \mathrm{~cm}^{-1}$ which may due to the involvement of $-\mathrm{OH}$ group during reduction of $\mathrm{Ag}$ ions to $\mathrm{Ag}$ nanoparticles [27]. Another peak was present at $1607 \mathrm{~cm}^{-1}$ in the C.N spectra which attributed to the carbonyl group of $\mathrm{C}=\mathrm{O}$ stretching vibration. However, the peak was disappeared in $\mathrm{Ag}_{\mathrm{B}}$ spectra and shifted to $1605 \mathrm{~cm}^{-1}$ in $\mathrm{Ag} \mathrm{CN}$ spectra, suggesting the binding of $\mathrm{C}=\mathrm{O}$ functional group with $\mathrm{Ag}$ nanoparticles [28]. The peak at $1083 \mathrm{~cm}^{-1}$ which attributes to the ether linkage $(\mathrm{C}-\mathrm{O}$ or $\mathrm{C}-\mathrm{O}-\mathrm{C})$ stretching vibrations was observed in $\mathrm{Ag}_{\mathrm{CN}}$, revealed that the phenolic compounds in C.N leaves extract have been successfully absorbed on the surface of $\mathrm{Ag}$ nanoparticles [29,30]. A new peak appeared at $483 \mathrm{~cm}^{-1}$ in $\mathrm{Ag}_{\mathrm{CN}}$ and $\mathrm{Ag}_{\mathrm{B}}$ spectra confirming the formation of $\mathrm{Ag}$ nanoparticles, while the small peak at $1318 \mathrm{~cm}^{-1}$ is refer to the $(\mathrm{C}-\mathrm{OH})$ group [31].

\subsection{Photocatalytic Activity}

Photocatalytic activity of $\mathrm{Ag}_{\mathrm{CN}}$ and $\mathrm{Ag}_{\mathrm{B}}$ nanoparticles was tested on degradation of
2,4-D under UV light irradiation. The 2,4-D degradation percentage (\%) was obtained at different interval of time was calculated using Equation (2).

$$
2,4-D \text { deg radation }(\%)=\frac{C_{0}-C_{t}}{C_{0}} \times 100
$$

where $C_{0}$ refer to the initial concentration of the reactant and $C_{t}$ is the reactant concentration after $t$ hours of exposure in light sources [32]. The results revealed that the rate degradation of 2,4-D escalated as the reaction time increases. Fig 4 illustrated that the presence of leaves extract in $\mathrm{Ag}_{\mathrm{CN}}$ leads to the higher degradation rate of $2,4-\mathrm{D}(98 \%)$.

This is mainly owed to the leaves extract that plays a crucial role as a capping agent which successfully produce a diminutive $\mathrm{Ag}_{\mathrm{CN}}$, which subsequently have a high catalytic activity towards the photodegradation of 2,4-D $[33,34]$. This result is also in agreement with previous studies reported which concluded that the size of nanoparticles have significant effect to the 2,4-D photocatalytic degradation [35]. However, the $\mathrm{Ag}_{\mathrm{B}}$ sample shows a much lower degradation percentage of 2,4-D (56\%) which confirms the absence of plant extract as a capping agent in the synthesized nanoparticles. Hence, the nanoparticles produced were much larger and resulted to the low photocatalytic activity.

In order to further illustrate the crucial role of the plant extract in Ag nanoparticles synthesis, the total phenolic content (TPC) of the plant extract was also determined. It was re-


Figure 5. (A) Photodegradation kinetics of 2,4-D at different initial concentrations; (B) The relationship between $1 / r_{0}$ and $1 / C_{0}$ at different initial concentrations of $2,4-\mathrm{D}$ 
markably found that $\mathrm{Ag}_{\mathrm{CN}}$ nanoparticles contain $6927.56 \mathrm{mg} / \mathrm{kg}$ of phenolic compound. The large number of the phenolic content may due to the simultaneous ultrasonic-hydrodistillation extraction method that provided much higher yield as compared to conventional aqueous extraction [12]. This results may be explained by the cavitation phenomena and mechanical mixing affect $[12,36]$. During the propagation of ultrasonic waves in ultrasoundassisted extraction, cavitation bubbles were generated at the surface of the solid matrix and causing a disruption of plant cell walls. Therefore, the extractable compounds was released with the increasing of contact surface area between solvent and plant material [37]. Consequently, the TPC analysis successfully proved that huge number of phenolic compound are greatly involved in the nanoparticles synthesis process and also significantly assists in the photocatalytic activity. Therefore, it can be concluded that the presence of plant extract ob-

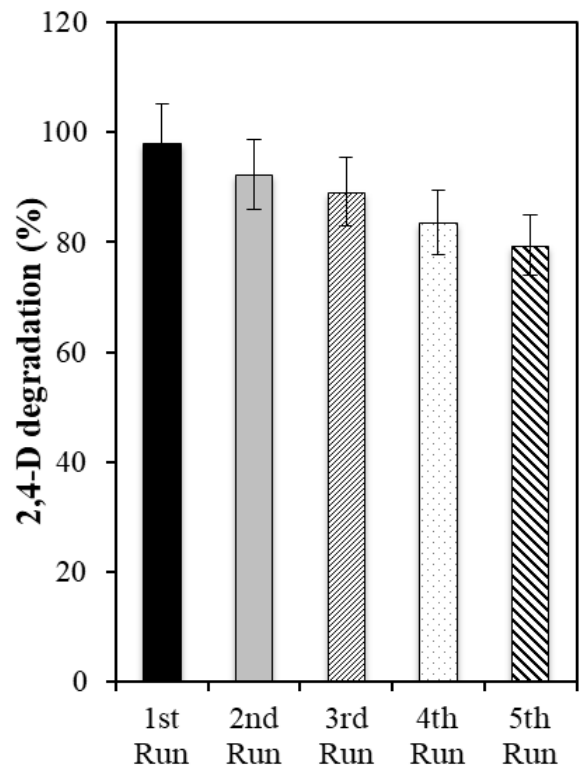

Figure 6. Reusability of $\mathrm{Ag}_{\mathrm{CN}}$ nanoparticles on degradation of $2,4-\mathrm{D}$ tained from the simultaneous extraction method with a huge number of phenolic compounds was essential for efficient nanoparticles synthesis and also degradation of 2,4-D.

\subsection{Kinetic Study}

Langmuir-Hinshelwood (LH) kinetics model is the most commonly employed kinetic expression to explain the kinetics of the heterogeneous catalytic processes. Based on LangmuirHinshelwood (L-H) which was illustrated in Equation (3) [38], the degradation rate of 2,4-D was studied and the linear plot of $\ln \left(C_{o} / C_{t}\right)$ vs time is shown in Figure 5 (A).

$$
r=-\frac{d C}{d t}=\frac{k_{r} K_{L H} C_{0}}{1+K_{L H} C_{0}}
$$

Where $r$ is the initial photocatalytic degradation rate $\left(\mathrm{mg} \cdot \mathrm{L}^{-1} \cdot \mathrm{min}^{-1}\right)$ of $2,4-\mathrm{D}, k_{r}$ the apparent reaction rate constant $\left(\mathrm{mg} \cdot \mathrm{L}^{-1} \cdot \mathrm{min}^{-1}\right), \mathrm{C}_{0}$ the initial concentration of 2,4-D (mg. $\left.\mathrm{L}^{-1}\right)$, and $\mathrm{K}_{\mathrm{LH}}$ is the adsorption equilibrium constant $\left(\mathrm{L} . \mathrm{mg}^{-1}\right)$ [39]. In cases where the chemical concentration, $C_{o}$ is small, the equation can be rearranged simply to an apparent first-order equation which illustrated in Equation (4) [40].

$$
\ln \left(\frac{C_{0}}{C_{t}}\right)=k_{r} K=K_{a p p} t
$$

Where $k_{r} K=K_{a p p}, C_{0}$ is the initial concentration of 2,4-D (mg. $\mathrm{L}^{-1}$ ), and $C_{t}$ is the concentration of $2,4-\mathrm{D}$ at time, $t$. The degradation rate also was deduced as shown in Equation (5):

$$
r=k_{a p p} C_{0}
$$

From the slope in Figure 5(A), the values of $k_{a p p}$ were determined and $r_{0}$ was calculated. Based on the tabulated data in Table 1, graph of $1 / r_{0}$ vs $1 / C_{0}$ was plotted. In addition, the parameter of $k_{r}$ and $K_{L H}$ also can be determined by linearizing the Equation (3) as shown in Equation (6).

Table 1. Pseudo-first-order apparent constant values for 2,4-D degradation

\begin{tabular}{ccc}
\hline Initial 2,4-D, Concentration, $C_{0}(\mathrm{mg} / \mathrm{L})$ & $\begin{array}{c}\text { Reaction rate, } k_{a p p} \\
\left(\mathrm{~min}^{-1}\right)\end{array}$ & $\begin{array}{c}\text { Initial reaction rate, } r_{0} \\
\left(\mathrm{mg} / \mathrm{L} \mathrm{min}^{-1}\right)\end{array}$ \\
\hline 5 & 0.0147 & 0.0735 \\
7.5 & 0.0158 & 0.1185 \\
10 & 0.0180 & 0.1800 \\
12.5 & 0.0150 & 0.1875 \\
80 & 0.0127 & 0.1905 \\
\hline
\end{tabular}




$$
\frac{1}{r_{0}}=\frac{1}{k_{r} K_{L H}} \frac{1}{C_{0}}+\frac{1}{k_{r}}
$$

The plot of $1 / r_{0}$ vs $1 / C_{0}$ in Figure $5(\mathrm{~B})$ gives a straight line result which proving that Langmuir-Hinshelwood (L-H) kinetics model was appropriate for the degradation of 2,4-D using $\mathrm{Ag}$ nanoparticles in leaves extract. From the graph, the values for the intercept of $1 / k_{r}$ and a slope of $1 / k_{r} K_{L H}$, was determined. Due to the value of $k_{r}\left(78.125 \mathrm{mg} . \mathrm{L}^{-1} \mathrm{~min}^{-1}\right)$ is larger than $K_{L H}$ (0.955 L.mg-1), it was suggested that the reaction occurs at the surface of the catalyst [41]. Hence, these results can be signified that the $\mathrm{Ag}_{\mathrm{CN}}$ nanoparticles was capable in increasing the rate of reaction for efficient photodegradation of 2,4-D.

\subsection{Reusability Study}

Reusability and recovery of the $\mathrm{Ag}_{\mathrm{CN}}$ catalysts have been studied for five consecutive runs in the degradation of 2,4-D. As presented in Figure 6, the catalyst revealed a desirable reusability with only minor reduction in its activity and it still could be reused for fifth consecutive cycles after separated from the reaction solution by filtration, washed several times with deionized water and dried in the oven. The result revealed an overall 19\% loss in 2,4-D degradation after the fifth cycle, demonstrating the stability and reusability of this catalyst. Referring to Jusoh et al. [18], the photocatalytic efficiency was declined due to decreasing active site of catalyst after adsorption of 2,4-D onto Ag catalyst surface.

\section{Conclusion}

The Ag nanoparticles were successfully synthesized via electrochemical method using Cymbopogon nardus leaves extract as a media. The phenolic compounds present in C.N leaves extract play an important role as a stabilizing and capping as well as reducing agent. Green synthesized Ag nanoparticles were ranged between 10-50 nm and found to be in spherical shape, which confirmed by XRD and TEM analysis. The Fourier-transform infrared (FTIR) spectroscopy results examined the occurrence of bioactive functional groups required for the reduction of $\mathrm{Ag}$ ions. The green synthesized Ag nanoparticles showed strong photocatalytic behavior in the degradation of toxic chemicals, which $98 \%$ of 2,4-D was degraded under UV light. The TPC analysis revealed that $\mathrm{Ag}_{\mathrm{CN}}$ nanoparticles contain large number of the phenolic content $(6927.56 \mathrm{mg} / \mathrm{kg})$ which may due to the simultaneous ultrasonichydrodistillation extraction method. The kinetic study confirms that the reaction process occurred on the catalysts surface and the catalyst was still stable after five cycles. These findings suggest that Cymbopogon nardus leaves extract is remarkably important for efficient nanoparticles synthesis and also degradation of 2,4-D.

\section{Acknowledgement}

The appreciation goes to the Ministry of Higher Education financial for the Fundamental Research Grant Scheme (Grant No. RDU160154) and University Malaysia Pahang for the Internal University Grant (Grant No. RDU180383). The gratefulness also goes to the Postgraduate Research Grants Scheme of UMP (Grant No. PGRS 180390 \& PGRS 180399) for financial supports of the students.

\section{References}

[1] Khoshnood, M., Azizian, S. (2012). Adsorption of 2, 4-dichlorophenoxyacetic acid pesticide by graphitic carbon nanostructures prepared from biomasses. Journal of Industrial and Engineering Chemistry, 18: 1796-1800.

[2] Shankar, M., Anandan, S., Venkatachalam, N., Arabindoo, B., Murugesan, V. (2006). Fine route for an efficient removal of 2,4dichlorophenoxyacetic acid (2,4-D) by zeolitesupported $\mathrm{TiO}_{2}$. Chemosphere, 63:1014-1021.

[3] Derakhshan, Z., Baghapour, M.A., Ranjbar, M., Faramarzian, M. (2013). Adsorption of methylene blue dye from aqueous solutions by modified pumice stone: kinetics and equilibrium studies. Health Scope, 2 :136-144.

[4] Hu, X., Sun, Z., Song, J., Zhang, G., Zheng, S. (2018). Facile synthesis of nano$\mathrm{TiO}_{2} /$ stellerite composite with efficient photocatalytic degradation of phenol. Advanced Powder Technology.

[5] Yin, R., Ling, L., Xiang, Y., Yang, Y., Bokare, A.D., Shang, C. (2018). Enhanced photocatalytic reduction of chromium (VI) by $\mathrm{Cu}$-doped $\mathrm{TiO}_{2}$ under UV-A irradiation. Separation and Purification Technology, 190: 53-59.

[6] Khani, R., Roostaei, B., Bagherzade, G., Moudi, M. (2018). Green synthesis of copper nanoparticles by fruit extract of Ziziphus spina-christi (L.) Willd.: Application for adsorption of triphenylmethane dye and antibacterial assay. Journal of Molecular Liquids, 255: 541-549.

[7] Mallikarjuna, K., Bathula, C., Buruga, K., Shrestha, N.K., Noh, Y.-Y., Kim, H. (2017). Green synthesis of palladium nanoparticles 
using fenugreek tea and their catalytic applications in organic reactions. Materials Letters, 205:138-141.

[8] Sur, U.K., Ankamwar, B., Karmakar, S., Halder, A., Das, P. (2018). Green synthesis of Silver nanoparticles using the plant extract of Shikakai and Reetha. Materials Today: Proceedings, 5: 2321-2329.

[9] Khodadadi, B., Bordbar, M., Nasrollahzadeh, M. (2017). Achillea millefolium L. extract mediated green synthesis of waste peach kernel shell supported silver nanoparticles: Application of the nanoparticles for catalytic reduction of a variety of dyes in water. Journal of Colloid and Interface Science, 493: 85-93.

[10] Anbuvannan, M., Ramesh, M., Viruthagiri, G., Shanmugam, N., Kannadasan, N. (2015). Anisochilus carnosus leaf extract mediated synthesis of zinc oxide nanoparticles for antibacterial and photocatalytic activitie. Materials Science in Semiconductor Processing, 39: 621-628.

[11] Nava, O., Luque, P., Gómez-Gutiérrez, C., Vilchis-Nestor, A., Castro-Beltrán, A., MotaGonzález, M., Olivas, A. (2017). Influence of Camellia sinensis extract on Zinc Oxide nanoparticle green synthesis. Journal of Molecular Structure, 1134: 121-125.

[12] Dranca, F., Oroian, M. (2016). Optimization of ultrasound-assisted extraction of total monomeric anthocyanin (TMA) and total phenolic content (TPC) from eggplant (Solanum melongena L.) peel. Ultrasonics Sonochemistry, 31: 637-646.

[13] Irfan, M., Moniruzzaman, M., Ahmad, T., Mandal, P.C., Bhattacharjee, S., Abdullah, B. (2017). Ionic liquid based extraction of flavonoids from Elaeis guineensis leaves and their applications for gold nanoparticles synthesis. Journal of Molecular Liquids, 241: 270-278.

[14] Mittal, A.K., Kumar, S., Banerjee, U.C. (2014). Quercetin and gallic acid mediated synthesis of bimetallic (silver and selenium) nanoparticles and their antitumor and antimicrobial potential. Journal of Colloid and Interface Science, 431: 194-199.

[15] Armani, M.A., Abu-Taleb, A., Remalli, N., Abdullah, M., Srikanth, V.V., Labhasetwar, N.K. (2016). Dragon's blood-aided synthesis of $\mathrm{Ag} / \mathrm{Ag}_{2} \mathrm{O}$ core/shell nanostructures and $\mathrm{Ag} / \mathrm{Ag}_{2} \mathrm{O}$ decked multi-layered graphene for efficient As (iii) uptake from water and antibacterial activity. RSC Advances, 6: 4414544153.

[16] Ahluwalia, V., Elumalai, S., Kumar, V., Kumar, S., Sangwan, R.S. (2018). Nano silver particle synthesis using Swertia paniculata herbal extract and its antimicrobial activity. Microbial Pathogenesis, 114: 402-408.
[17] Kumar, V., Gundampati, R.K., Singh, D.K., Jagannadham, M.V., Sundar, S., Hasan, S.H. (2016). Photo-induced rapid biosynthesis of silver nanoparticle using aqueous extract of Xanthium strumarium and its antibacterial and antileishmanial activity. Journal of Industrial and Engineering Chemistry, 37: 224236.

[18] Jusoh, R., Jalil, A., Triwahyono, S., Idris, A., Noordin, M. (2015). Photodegradation of 2chlorophenol over colloidal $\alpha-\mathrm{FeOOH}$ supported mesostructured silica nanoparticles: Influence of a pore expander and reaction optimization. Separation and Purification Technology, 149: 55-64.

[19] Fattahi, S., Zabihi, E., Abedian, Z., Pourbagher, R., Ardekani, A.M., Mostafazadeh, A., Akhavan-Niaki, H. (2014). Total phenolic and flavonoid contents of aqueous extract of stinging nettle and in vitro antiproliferative effect on hela and BT-474 Cell lines. International Journal of Molecular and Cellular Medicine, 3: 102-107.

[20] Verma, D.K., Hasan, S.H., Banik, R.M. (2016). Photo-catalyzed and phyto-mediated rapid green synthesis of silver nanoparticles using herbal extract of Salvinia molesta and its antimicrobial efficacy. Journal of Photochemistry and Photobiology B: Biology, 155: 51-59.

[21] Rajakumar, G., Gomathi, T., Thiruvengadam, M., Rajeswari, V.D., Kalpana, V., Chung, I.M. (2017). Evaluation of anti-cholinesterase, antibacterial and cytotoxic activities of green synthesized silver nanoparticles using from Millettia pinnata flower extract. Microbial pathogenesis, 103: 123-128.

[22] Saraswathi, V.S., Tatsugi, J., Shin, P.-K., Santhakumar, K. (2017). Facile biosynthesis, characterization, and solar assisted photocatalytic effect of $\mathrm{ZnO}$ nanoparticles mediated by leaves of L. speciosa. Journal of Photochemistry and Photobiology B: Biology, 167: 89-98.

[23] Nava, O., Soto-Robles, C., Gómez-Gutiérrez, C., Vilchis-Nestor, A., Castro-Beltrán, A., Olivas, A., Luque, P. (2017). Fruit peel extract mediated green synthesis of zinc oxide nanoparticles. Journal of Molecular Structure, 1147: 1-6.

[24] Anjum, S., Abbasi, B.H. (2016). Biomimetic synthesis of antimicrobial silver nanoparticles using in vitro-propagated plantlets of a medicinally important endangered species: Phlomis bracteosa. International Journal of Nanomedicine, 11: 1663-1675.

[25] Lakshmanan, G., Sathiyaseelan, A., Kalaichelvan, P., Murugesan, K. (2017). Plant-mediated synthesis of silver nanoparticles using fruit extract of Cleome viscosa L.: 
Assessment of their antibacterial and anticancer activity. Karbala International Journal of Modern Science, 4: 61-68.

[26] Arunachalam, R., Dhanasingh, S., Kalimuthu, B., Uthirappan, M., Rose, C., Mandal, A.B. (2012). Phytosynthesis of silver nanoparticles using Coccinia grandis leaf extract and its application in the photocatalytic degradation. Colloids and Surfaces B: Biointerfaces, 94: 226-230.

[27] Saraswathi, V.S., Santhakumar, K. (2017). Photocatalytic activity against azo dye and cytotoxicity on MCF-7 cell lines of zirconium oxide nanoparticle mediated using leaves of Lagerstroemia speciosa. Journal of Photochemistry and Photobiology B: Biology, 169: 47-55.

[28] Ramesh, P., Kokila, T., Geetha, D. (2015). Plant mediated green synthesis and antibacterial activity of silver nanoparticles using Emblica officinalis fruit extract. Spectrochimica Acta Part A: Molecular and Biomolecular Spectroscopy, 142: 339-343.

[29] Saravanan, A., Kumar, P.S., Devi, G.K., Arumugam, T. (2016). Synthesis and characterization of metallic nanoparticles impregnated onto activated carbon using leaf extract of Mukia maderasapatna: Evaluation of antimicrobial activities. Microbial Pathogenesis, 97: 198-203.

[30] Varadavenkatesan, T., Vinayagam, R., Selvaraj, R. (2017). Structural characterization of silver nanoparticles phyto-mediated by a plant waste, seed hull of Vigna mungo and their biological applications. Journal of Molecular Structure, 1147: 629-635.

[31] Siripireddy, B., Mandal, B.K. (2017). Facile green synthesis of zinc oxide nanoparticles by Eucalyptus globulus and their photocatalytic and antioxidant activity. Advanced Powder Technology, 28: 785-797.

[32] Kumar, B., Smita, K., Cumbal, L., Debut, A. (2015). Ultrasound agitated phytofabrication of palladium nanoparticles using Andean blackberry leaf and its photocatalytic activity. Journal of Saudi Chemical Society, 19: 574580.
[33] Ahmed, M. (2012). Synthesis and structural features of mesoporous $\mathrm{NiO} / \mathrm{TiO}_{2}$ nanocomposites prepared by sol-gel method for photodegradation of methylene blue dye. Journal of Photochemistry and Photobiology A: Chemistry, 238: 63-70.

[34] Borodina, V., Mirgorod, Y.A. (2014). Kinetics and mechanism of the interaction between $\mathrm{HAuCl} 4$ and rutin. Kinetics and Catalysis, 55: 683-687.

[35] Zielińska-Jurek, A., Klein, M., Hupka, J. (2017). Enhanced visible light photocatalytic activity of $\mathrm{Pt} / \mathrm{I}-\mathrm{TiO}_{2}$ in a slurry system and supported on glass packing. Separation and Purification Technology, 189: 246-252.

[36] Ince, A.E., Sahin, S., Sumnu, G. (2014). Comparison of microwave and ultrasound-assisted extraction techniques for leaching of phenolic compounds from nettle, Journal of Food Science and Technology, 51: 2776-2782.

[37] Saleh, I.A., Vinatoru, M., Mason, T., AbdelAzim, N., Aboutabl, E., Hammouda, F. (2016). A possible general mechanism for ultrasound-assisted extraction (UAE) suggested from the results of UAE of chlorogenic acid from Cynara scolymus L.(artichoke) leaves. Ultrasonics Sonochemistry, 31: 330-336.

[38] Nagajyothi, P., Pandurangan, M., Vattikuti, S., Tettey, C., Sreekanth, T., Shim, J. (2017). Enhanced photocatalytic activity of $\mathrm{Ag} / \mathrm{g}-\mathrm{C}_{3} \mathrm{~N}_{4}$ composite. Separation and Purification Technology, 188: 228-237.

[39] Idris, A., Hassan, N., Rashid, R., Ngomsik, A.-F. (2011). Kinetic and regeneration studies of photocatalytic magnetic separable beads for chromium (VI) reduction under sunlight. Journal of Hazardous Materials, 186: 629635.

[40] Feng, X., Guo, H., Patel, K., Zhou, H., Lou, X. (2014). High performance, recoverable $\mathrm{Fe}_{3} \mathrm{O}_{4} \mathrm{ZnO}$ nanoparticles for enhanced photocatalytic degradation of phenol. Chemical Engineering Journal, 244: 327-334.

[41] Jaafar, N., Jalil, A., riwahyono, S. , Efendi, TJ., Mukti, R., Jusoh, R., Jusoh, N., Karim, A., Salleh, N., Suendo, V. (2015). Direct in situ activation of Ag0 nanoparticles in synthesis of $\mathrm{Ag} / \mathrm{TiO}_{2}$ and its photoactivity. $\mathrm{Ap}$ plied Surface Science, 338: 75-84.

Selected and Revised Papers from The $4^{\text {th }}$ International Conference of Chemical Engineering \& Industrial Biotechnology (ICCEIB 2018) (http://icceib.ump.edu.my/index.php/en/) (Universiti Malaysia Pahang, by 1st_2nd August 2018) after Peer-reviewed by Scientific Committee of ICCEIB 2018 and Peer-Reviewers of Bulletin of Chemical Reaction Engineering \& Catalysis 